\title{
PENGENDALIAN PENGGUNAAN KENDARAAN PRIBADI DENGAN STRATEGI PARKIR DAN ERP DI SUDIRMAN - THAMRIN (DKI JAKARTA)
}

\author{
Petrick Dwi Saputra ${ }^{1}$ dan Najid ${ }^{2}$ \\ ${ }^{1}$ Program Studi Sarjana Sipil, Universitas Tarumanagara Jl.Let Jend S Parman No 1, Jakarta \\ Email:petrickdwisaputra@yahoo.co.id \\ 2 Program Studi Sarjana Sipil, Universitas Tarumanagara Jl.Let Jend S Parman No 1, Jakarta \\ Email: najid2009@yahoo.com
}

\begin{abstract}
ABSTRAK
Skripsi ini membahas pengendalian penggunaan kendaraan pribadi dengan penerapan strategi Electronic Road Pricing dan kebijakan parkir. Tujuan dari penelitian ini adalah untuk menganalisis tingkat keinginan dari masyarakat terhadap dua sistem tesebut jika diterapkan di kota Jakarta. Pada dua sistem tersebut mempunyai cara kerja yang berbeda dalam mengatasi kemacetan dan pengendalian kendaraan pribadi. Electronic Road Pricing telah berhasil diterapkan di beberapa negara di dunia, salah satunya Singapura negara pertama di dunia yang menerapkan sistem Electronic Road Pricing dalam menanggulangi kemacetan. Sedangkan sistem kebijakan parkir merupakan sistem dimana untuk menggurangi kendaraan pribadi maka tarif parkir akan dinaikan dengan tinggi sesuai dengan kepadatan penggunaan kendaraan pribadi di daerah tersebut dan pada daerah padat perkantoran. Hal ini bertujuan agar pengguna kendaraan pribadi beralih menggunakan kendaraan umum untuk menggurangi kemacetan. Penelitian ini mengambil data dengan cara penyebaran kuesioner di jalan Sudirman - Thamrin dan responden yang melewati jalan tersebut, agar dapat mengetahui pilihan dari responden, setelah data sudah terkumpul di analisis agar dapat mengetahui pilihan dari responden tentang kedua sistem tersebut dengan menggunakan model analisis sensitifitas terhadap sistem ERP dan parkir yang berhubungan dengan total responden ,pendapatan responden ,dan kendaraan umum yang digunakan responden sehari - hari untuk mengetahui keinginan responden pada kedua sistem tersebut. Hasil dari penelitian ini adalah ketika strategi ERP dan parkir diterapkan dengan tarif yang tinggi maka pengguna jalan Sudirman - Thamrin akan beralih menggunakan kendaraan umum.
\end{abstract}

Kata kunci: Strategi Electronic Road Pricing , Strategi Kebijakan Parkir ,pengendalian kendaraan pribadi, model analisis sensitifitas

\section{PENDAHULUAN}

\section{Latar Belakang}

Pesatnya pertumbuhan kendaraan di Jakarta serta minimnya ruang bagi kendaraan untuk lewat inilah yang menjadi faktor utama terjadinya kemacetan. Electronic Road Pricing (ERP) menggunakan sistem pengenaan biaya secara langsung terhadap pengguna jalan karena melewati ruas jalan tertentu. Pada dasarnya terdapat dua tujuan dari pengenaan ERP yaitu untuk menambah pendapatan suatu daerah atau negara, atau suatu sarana untuk mengatur penggunaan kendaraan agar tidak terjadi kemacetan. Selanjutnya, untuk sistem pengendalian parkir dilakukan agar pemilik kendaraan pribadi lebih memilih angkutan umum dikarnakan tarif yang terbilang lebih murah untuk angkutan umum sehingga dapat mengurangi kendaraan yang beroperasi di wilayah Jakarta. 

Jakarta)

\section{Tujuan Penelitian}

1. Untuk mengetahui perbandingan sistem Electronic Road Pricing (ERP) dengan sistem pengendalian kebijakan parkir, serta membandingkan kedua sistem tersebut terhadap rata - rata pendapatan penghasilan dan penggunaan kendaraan pribadi mobil.

2. Membandingkan kebijakan parkir terhadap pengguna Transjakarta dan taxi online.

3. Membandingkan sistem Electronic Road Pricing (ERP) terhadap pengguna Transjakarta dan taxi online.

\section{Electronic Road Pricing (ERP)}

Menurut Susantono (2010) Electronic Road Pricing adalah pengenaan biaya secara langsung terhadap pengguna jalan karena melewati ruas jalan tertentu. Pada dasarnya terdapat dua tujuan dari penggenaan Electronic Road Pricing yaitu untuk menambah pendapatan suatu daerah atau negara, atau suatu sarana untuk mengatur penggunaan kendaraan agar tidak terjadi kemacetan. Tujuan utama dari Electronic Road Pricing, yaitu mengurangi kemacetan, menjadi sumber pendapatan daerah, mengurangi dampak lingkungan, dan mendorong pengguna angkutan massal.

\section{Penerapan Electronic Road Pricing (ERP)}

Menurut Dinas Perhubungan DKI Jakarta (2011). Latar belakang diterapkanya ERP adalah daya dukung jalan di Jakarta tidak memadai, kerugian akibat kemacetan sangat tinggi, degredasi sistem angkutan umum, dan tren pertumbuhan jumlah kendaraan bermotor yang sangat tinggi.

Kemacetan akan memberi dampak negatif, baik dalam aspek sosial, lingkungan, maupun ekonomi. Dampak negatif tersebut diantaranya pemborosan bahan bakar minyak (BBM), peningkatan polusi udara, dan penurunan mobalitas. Sebelumnya pemerintah provinsi DKI Jakarta telah menerapkan aturan three in one (3 in 1) dan ganjil genap di beberapa ruas jalan di ibu kota. Hal ini dimaksudkan untuk membatasi jumlah kendaraan pada jam-jam sibuk sehingga kemacetan dapat dikurangi. Namun, dalam pelaksanaanya aturan tersebut dinilai tidak efektif dalam mengatasi kemacetan.

Tujuannya adalah untuk mengatasi berbagai masalah yang ditimbulkan akibat kemacetan. Mekanisme penerapan ERP adalah setiap kendaraan yang melintasi zona ERP dikenakan sejumlah biaya tertentu

\section{Pengendalian Strategi ERP}

Menurut Sumitimo (2008) permasalahan transportasi perkotaan di Jakarta mempunyai kecendrungan semakin bertambah parah. Apabila terus dibiarkan, maka bukan tidak mungkin Jakarta akan mengalami kemacetan yang sangat parah atau bahkan macet total pada jam-jam sibuk.ERP diharapkan mampu mengurangi perjalanan dengan kendaraan pribadi dan menguragi perjalanan yang tidak perlu, terutama pada jam-jam sibuk.

\section{Manfaat Electronic Road Pricing (ERP)}

Menurut dinas perhubungan DKI Jakarta (2011), manfaat Electronic Road Pricing (ERP), diantaranya:

1. Pemerintah :

- Mengurangi kemacetan

- Sumber pendapatan baru dari lalu lintas

- Mempermudah penerapan pembatasan lalu lintas

2. Pengendara :

- Kenyamanan berkendara

- Perjalanan menjadi lebih teapat waktu

- Kemudahan pembayaran

3. Masyarakat :

- Mengurangi kebisingan yang dihasilkan kendaraan

- Menurunkan tingkat polusi udara yang berasal dari asap kendaraan

- Minimalisasi kerugian ekonomi akibat kemacetan lalu lintas

\section{Dampak Electronic Road Pricing}

1. Tercapainya efisiensi dalam aspek transportasi seperti tercapainya kelancaran lalu lintas yang menyebabkan penghematan waktu tempuh dan biaya perjalanan. 
2. Peningkatan kualitas lingkungan, TDM (Travel Demand Managemennt) dalam aspek lingkungan diharapkan dapat mengurangi polusi udara, dan mengurangi polusi bunyi dan getaran.

3. Penataan sistem tata guna lahan, TDM diharapkan dapat merevitalisasi fasilitas perkotaan sesuai dengan fungsinya.

4. Meningkatkan ekonomi < TDM diharapkan dapat memberikan pendapatan tambahan bagi pemerintahan sehingga mendapat dan tambahan untuk meningkatkan kualitas angkutan umum.

5. Menjamin persamaan hak pengguna jalan, TDM diharapkan dapat memberikan keadilan bagi pengguna jalan dengan memberikan kewajiban yang lebih berat bagi pengguna jalan yang lebih berkontribusi terhadap kemacetan. Selain itu, jaminan terhadap pejalan kaki dan penghuni daerah lokal pun diharapkan dapat terealisai.

\section{Pengendalian Parkir}

Pengendalian parkir dilakukan untuk mendorong penggunaan sumber daya parkir secara lebih efisien serta digunakan juga sebagai alat untuk membatasi arus kendaraan ke suatu kawasan yang perlu dibatasi lalu lintasnya. Pengendalian parkir merupakan alat manajemen kebutuhan lalu lintas yang biasa digunakan untuk mengendalikan kendaraan yang akan menuju suatu kawasan ataupun perkantoran tertentu sehingga dapat diharapkan akan terjadi peningkatan kinerja lalu lintas di kawasan tersebut.

\section{Strategi Pengendalian Parkir}

Pengendalian parkir bertujuan untuk mengurangi masalah parkir seperti kemacetan serta berkurangnya sistem jaringan jalan. Pada jaringan jalan menuju pusat kota akan lebih besar hambatannya akibat parkir dan kebutuhan parkir (suplai), maka peranan ruang, waktu dan ongkos parkir (tarif) sebagai wacana pengendalian parkir sangat berpengaruh. Kebijaksanaan ini sangat efektif untuk meningkatkan pelayanan jaringan jalan, meliputi :

1. Pembatasan lokasi/ ruang parkir, dimaksudkan untuk mengendalikan arus lalu lintas kendaraan pribadi ke suatu daerah tertentu, atau untuk membebaskan koridor/ kawasan tertentu dari pengaruh parkir untuk tujuan kelancaran arus lalu lintas.

2. Pembatasan dan pengendalian waktu parkir dilakukan pada jam-jam sibuk.

3. Penetapan tarif parkir optimal yaitu dengan menaikkan tarif parkir.

4. Pembatasan wilayah parkir pada sistem jaringan jalan.

\section{Kebijakan Tarif Parkir}

Menurut Abubakar (2011) tarif parkir merupakan alat yang sangat bermanfaat untuk mengendalikan jumlah kendaraan yang parkir. Beberapa kota besar didunia bahkan menerapkan tarif yang sangat tinggi. Pada tabel berikut ditunjukkan besarnya pengeluaran untuk parkir di beberapa kota besar.Dengan dasar hukum permintaan dalam teori ekonomi dapat diterapkan kebijakan tarif. Dengan semakin tingginya tarif, maka diharapkan jumlah pengguna ruang parkir berkurang.

\section{Analisis Sensitivitas dan Linear Regression}

Analisis sensitivitas merupakan analisis yang dilakukan pada solusi optimal suatu persolan program linear karna adanya perubahan parameter untuk melihat berapa besar perubahan dapat ditolerir sebelum solusi optimal mulai kehilangan optimalitasnya. Program linear merupakan suatu metode penyelesaian untuk memperoleh solusi optimal (maksimum/minimum) dari suatu persoalan. Salah satu tipe khusus dari persoalan program linear adalah persoalan transportasi. (Irawan, 2015)

Regresi linier adalah metode statistika yang digunakan untuk membentuk model hubungan antara variabel terikat (dependen; respon; Y) dengan satu atau lebih variabel bebas (independen, prediktor, X). Apabila banyaknya variabel bebas hanya ada satu, disebut sebagai regresi linier sederhana, sedangkan apabila terdapat lebih dari 1 variabel bebas, disebut sebagai regresi linier berganda. Analisis regresi setidak-tidaknya memiliki 3 kegunaan, yaitu untuk tujuan deskripsi dari fenomena data atau kasus yang sedang diteliti, untuk tujuan kontrol, serta untuk tujuan prediksi. Namun yang perlu diingat, prediksi di dalam konsep regresi hanya boleh dilakukan di dalam rentang data dari variabel-variabel bebas yang digunakan untuk membentuk model regresi tersebut, bentuk persamaan regresi linear sebagai berikut : 


$$
\begin{aligned}
& (\mathrm{n} \cdot \Sigma \mathrm{xy})-(\Sigma \mathrm{x} \cdot \Sigma \mathrm{y}) \\
& b=\left(\mathrm{n} \cdot \Sigma \mathrm{x}^{2}\right)-(\Sigma \mathrm{x} \cdot \Sigma \mathrm{x}) \\
& a=- \\
& \text { n } \\
& \text { b. } \Sigma \mathrm{x} \\
& n \\
& Y=a+b . X
\end{aligned}
$$

\section{Dimana :}

$$
\begin{array}{ll}
\mathrm{Y} & =\text { Variabel hasil prediksi } \\
\mathrm{a} & =\text { Konstanta kurva linear } \\
\mathrm{b} & =\text { Koefisiensi parameter laju } \\
\mathrm{X} & =\text { Pertumbuhan beban Variabel } \\
\mathrm{n} & =\text { Jumlah data }
\end{array}
$$

\section{METODOLOGI PENELITIAN}

Agar pelaksanaan penelitian efektif dan efisien, diperlukan metodologi penelitian yang runtut. Sehingga setiap tahap kegiatan yang dilakukan dapat lebih terarah untuk mencapai tujuan dan hasil yang diharapkan. Langkah penelitian adalah sebagai berikut:

$\begin{array}{ll}\text { Tahap I } & \text { : Penetapan Tujuan, Metode Pengumpulan dan Analisis } \\ \text { Tahap II } & \text { : Identifikasi Masalah } \\ \text { Tahap III } & \text { : Penentuan Lokasi } \\ \text { Tahap IV } & \text { : Pembuatan Fomulir Survey } \\ \text { Tahap V } & \text { : Perbaikan Formulir Survey } \\ \text { Tahap VI } & \text { : Pengambilan Data } \\ \text { Tahap VII } & \text { : Kompilasi Data } \\ \text { Tahap VIII } & \text { : Kesimpulan dan Saran }\end{array}$

\section{Metode Pengumpulan Data}

Metode pengumpulan data dalam penelitian tentu dipengaruhi oleh permasalahan yang akan diangkat. Oleh karena itu sangat penting untuk mengetahui dan memahami berbagai bentuk teknik pengumpulan data. Berdasarkan data yang telah dikumpulkan baik data primer maupun sekunder dilakukan penyusunan data, pengolahan, dan analisis data.Setelah turun ke lapangan, Setelah mendapatkan data mentah, maka dapat melakukan analisis data dan diolah dengan menggunakan rumus linear regression dan didapatkan hasil grafik model analisis sensitivitas dari perhitungan tersebut dengan memasukkan data yang telah diperoleh. 


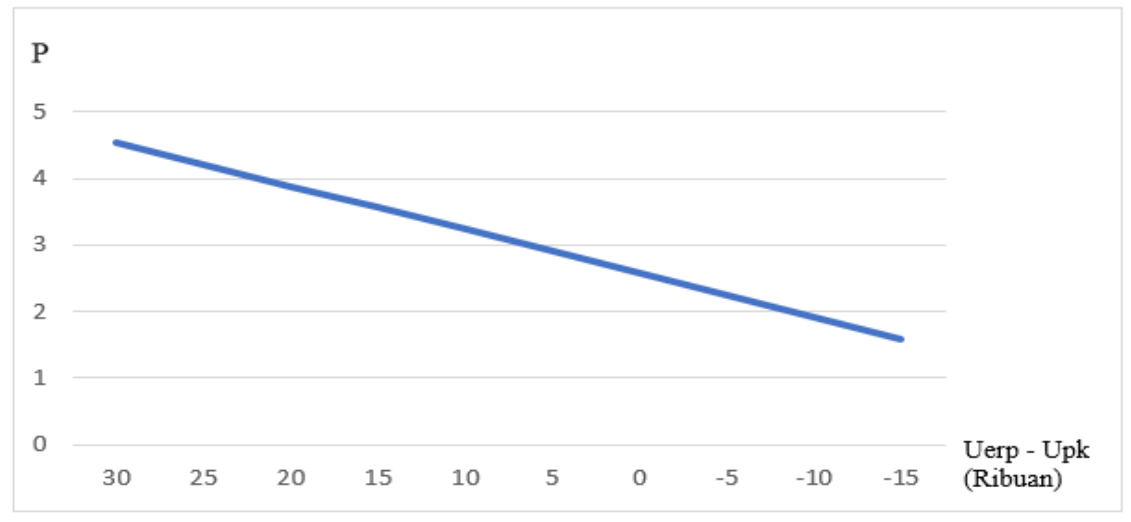

Grafik 1 Hubungan Selisih Utilitas ERP dan Parkir Terhadap Pilihan Parkir

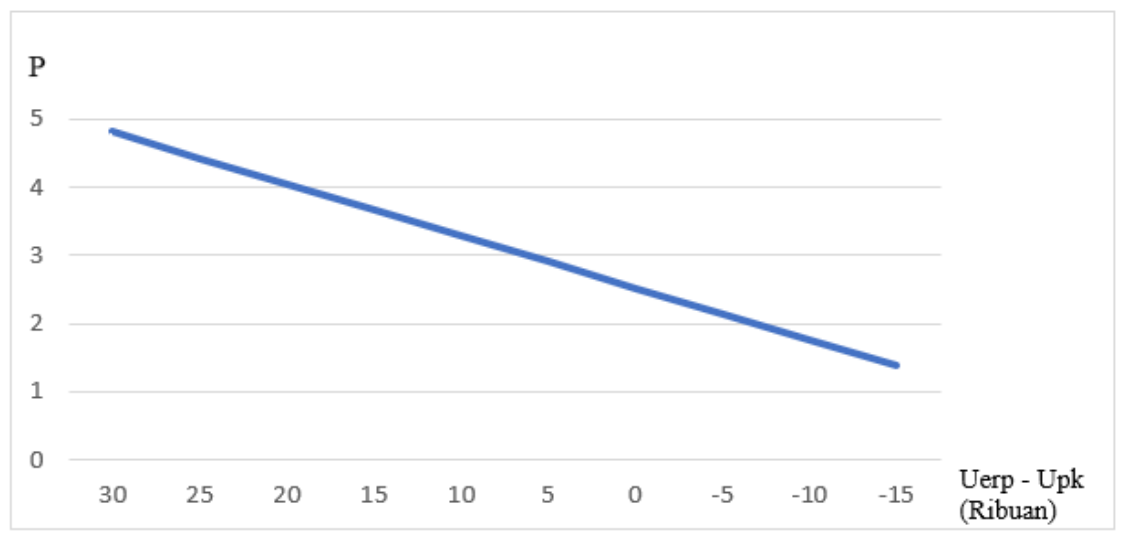

Grafik 2 Hubungan Selisih Utilitas Pada Pendapatan Lebih dari 7 Juta Terhadap Pilihan Parkir

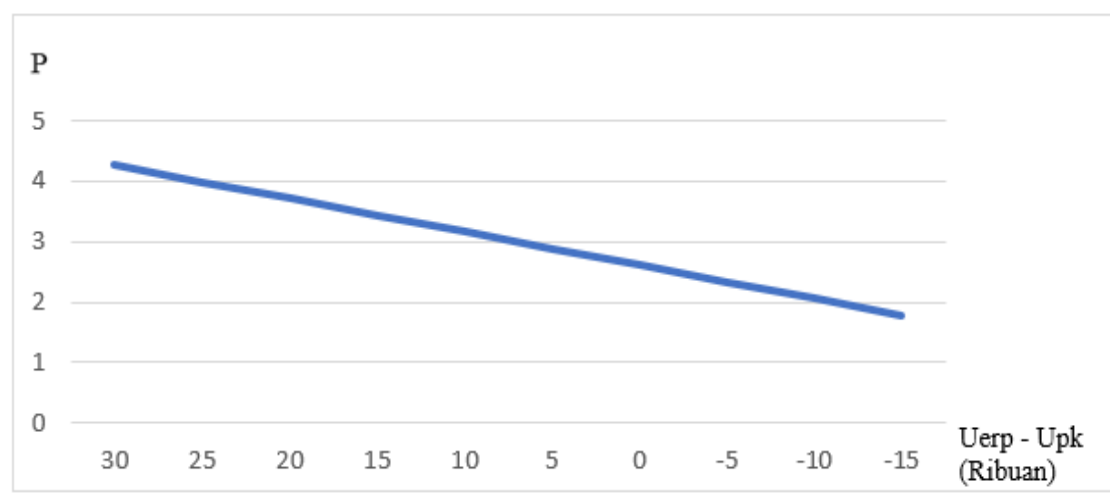

Grafik 3 Hubungan Selisih Utilitas Pada Pendapatan kurang dari 7 Juta Terhadap Pilihan Parkir 
Pengendalian Penggunaan Kendaraan Pribadi dengan Strategi Parkir dan ERP di Sudirman - Thamrin (DKI Jakarta)

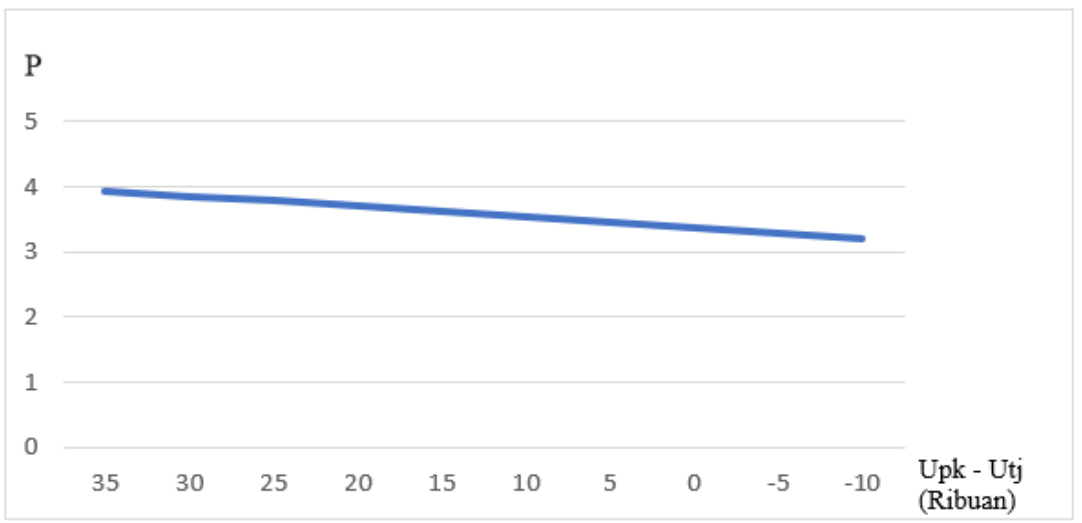

Grafik 5 Hubungan Selisih Utilitas Parkir dan Transjakarta Terhadap Pilihan Transjakarta

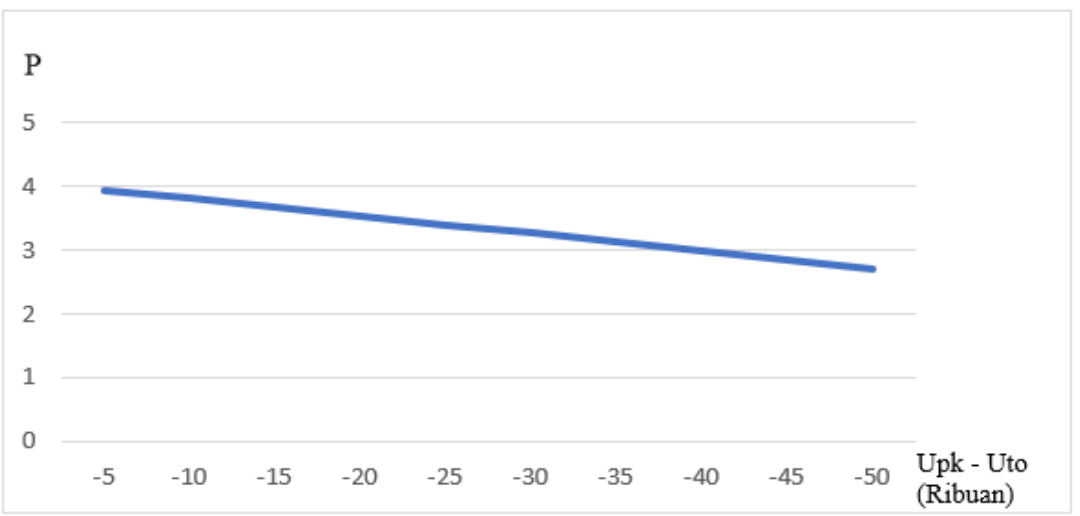

Grafik 6 Hubungan Selisih Utilitas Parkir dan Taxi Online Terhadap Pilihan Taxi Online

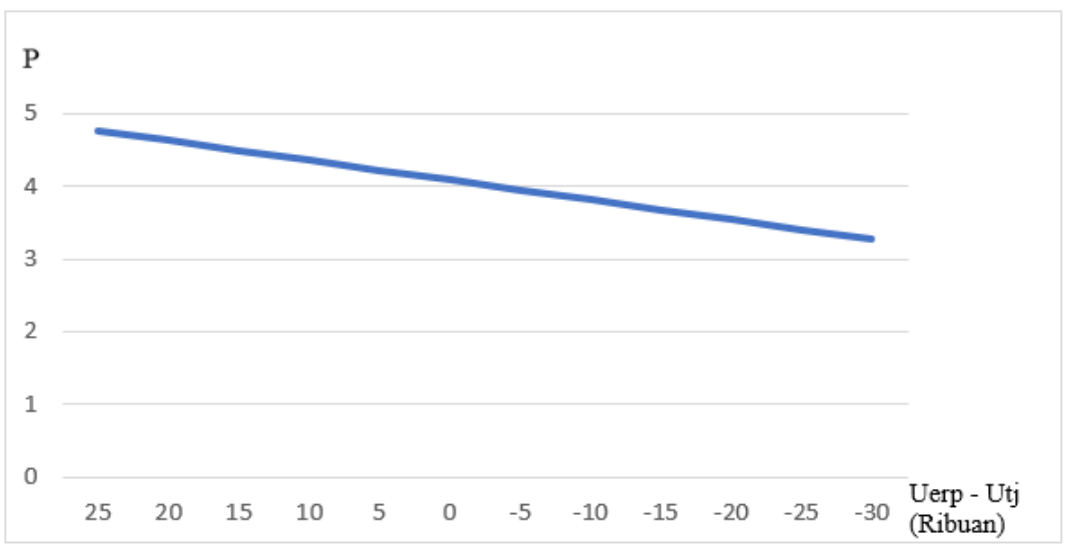

Grafik 7 Hubungan Selisih Utilitas ERP dan Transjakarta Terhadap Pilihan Transjakarta 


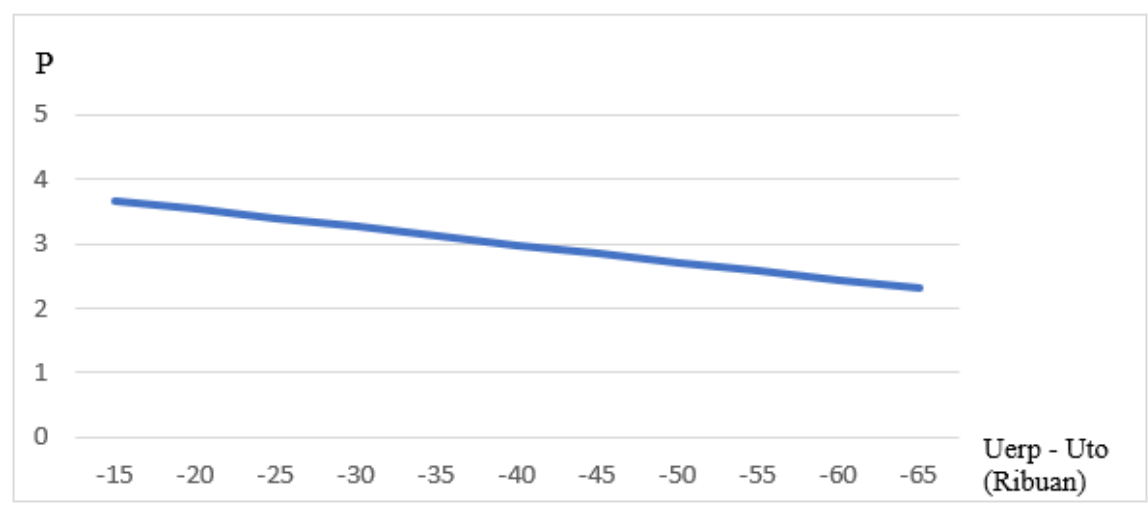

Grafik 8 Hubungan Selisih Utilitas ERP dan Taxi Online Terhadap Pilihan Taxi Online

\section{ANALISIS}

\section{Analisis Sensitivitas model Pilihan Parkir Terhadap Utilitas ERP dan Parkir}

Pada tabel ini dapat dilihat sensitivitas pilihan parkir terhadap utilitas ERP dan parkir untuk model total, model pendapatan lebih dari 7 juta, model pendapatan kurang dari 7 juta dari model tersebut akan didapatkan analisis sensitivitas yang dapat dilihat pada tabel 1 dibawah ini.

Tabel 1 Analisis Sensitivitas Model ERP dan Parkir

\begin{tabular}{|c|c|c|c|}
\hline ERP - Parkir (Rp) & Total Responden & Pendapatan > 7 juta & Pendapatan < 7 juta \\
\hline 30.000 & 4,543 & 4,810 & 4,273 \\
\hline 25.000 & 4,215 & 4,429 & 3,996 \\
\hline 20.000 & 3,887 & 4,048 & 3,719 \\
\hline 15.000 & 3,559 & 3,667 & 3,442 \\
\hline 10.000 & 3,231 & 3,286 & 3,165 \\
\hline 5.000 & 2,903 & 2,903 & 2,888 \\
\hline 0 & 2,575 & 2,524 & 2,611 \\
\hline-5.000 & 2,247 & 2,143 & 2,334 \\
\hline-10.000 & 1,919 & 1,762 & 2,057 \\
\hline-15.000 & 1,591 & 1,381 & 1,780 \\
\hline
\end{tabular}

Dari Tabel 1 diatas didapatkan hasil anilisis sensitivitas dengan selisih setiap harga Rp 5.000, pilihan parkir terhadap utilitas ERP dan parkir semakin besar biaya ERP maka responden lebih memilih parkir, dan semakin besar biaya parkir maka responden lebih memilih ERP. Hal ini dapat dilihat terjadi penurunan sensitivitas pada selisih $10.000-5.000$.

\section{Analisis Sensitivitas Model Pilihan Transjakarta terhadap utilitas Parkir dan Transjakarta}

Pada tabel ini dapat dilihat model sensitivitas pilihan Transjakarta terhadap utilitas parkir dan Transjakarta pada tabel 2 di bawah ini 
Pengendalian Penggunaan Kendaraan Pribadi dengan Strategi Parkir dan ERP di Sudirman - Thamrin (DKI Jakarta)

Tabel 2 Analisis Sensitivitas Model Parkir dan Transjakarta

\begin{tabular}{|c|c|}
\hline $\begin{array}{c}\text { Parkir - Transiakarta } \\
(\mathrm{R} p)\end{array}$ & Transiakarta \\
\hline 35.000 & 3,943 \\
\hline 30.000 & 3,861 \\
\hline 25.000 & 3,778 \\
\hline 20.000 & 3,696 \\
\hline 15.000 & 3,613 \\
\hline 10.000 & 3,531 \\
\hline 5.000 & 3,448 \\
\hline 0 & 3,366 \\
\hline-5.000 & 3,283 \\
\hline-10.000 & 3,201 \\
\hline
\end{tabular}

Dari Tabel 2 diatas didapatkan hasil anilisis sensitivitas dengan selisih setiap harga Rp 5.000, pilihan Transjakarta terhadap utilitas parkir dan Transjakarta dapat dilihat bahwa responden yang memilih Transjakarta sebagai kendaraan sehari - hari masih ragu - ragu dan mungkin memilih kendaraan umum dibandingkan untuk memilih kendaraan pribadi terhadap selisih pilihan parkir, penurunan sensitivitas dengan selisih yg ditentukan tidak terbilang jauh.

\section{Analisis Sensitivitas Model Pilihan Taxi Online Terhadap Utilitas Parkir dan Taxi Online}

Pada tabel ini dapat dilihat model sensitivitas pilihan Taxi Online terhadap utilitas parkir dan Taxi Online pada Tabel 3 di bawah ini.

Tabel 3 Analisis Sensitivitas Utilitas Parkir dan Taxi Online

\begin{tabular}{|c|c|}
\hline $\begin{array}{c}\text { Parkir - Taxi Online } \\
(\mathrm{R} p)\end{array}$ & $\begin{array}{c}\text { Taxi } \\
\text { Online }\end{array}$ \\
\hline-5.000 & 3,947 \\
\hline-10.000 & 3,810 \\
\hline-15.000 & 3,673 \\
\hline-20.000 & 3,536 \\
\hline-25.000 & 3,399 \\
\hline-30.000 & 3,262 \\
\hline-35.000 & 3,125 \\
\hline-40.000 & 2,988 \\
\hline-45.000 & 2,851 \\
\hline-50.000 & 2,714 \\
\hline
\end{tabular}

Dari tabel diatas didapatkan hasil anilisis sensitivitas dengan selisih setiap harga Rp 5.000, pilihan taxi online terhadap utilitas parkir dan taxi online dapat dilihat bahwa semakin besarnya biaya parkir responden yang memilih Taxi Online sebagai kendaraan sehari - hari masih ragu - ragu dan mungkin memilih kendaraan umum dibandingkan kendaraan pribadi pada pilihan parkir. Penurunan sensitivitasny dapat dilihat pada selisih $35.000-$ 40.000 .

\section{Analisis Sensitivitas Model Pilihan Transjakarta Terhadap Utilitas ERP dan Transjakarta}

Pada tabel ini dapat dilihat model sensitivitas pilihan Transjakarta terhadap utilitas ERP dan Transjakarta pada Tabel 4 di bawah ini. 
Tabel 4 Analisis Sensitivitas Model ERP dan Transjakarta

\begin{tabular}{|c|c|}
\hline ERP - Transjakarta (RD) & Transjakarta \\
\hline 25.000 & 4,769 \\
\hline 20.000 & 4,632 \\
\hline 15.000 & 4,495 \\
\hline 10.000 & 4,358 \\
\hline 5.000 & 4,221 \\
\hline 0 & 4,084 \\
\hline-5.000 & 3,947 \\
\hline-10.000 & 3,810 \\
\hline-15.000 & 3,673 \\
\hline-20.000 & 3,536 \\
\hline-25.000 & 3,399 \\
\hline-30.000 & 3,262 \\
\hline
\end{tabular}

Dari Tabel 4 diatas didapatkan hasil anilisis sensitivitas dengan selisih setiap harga Rp 5.000, pilihan Transjakarta terhadap utilitas ERP dan Transjakarta dapat dilihat bahwa semakin besar biaya ERP responden yang memilih Transjakarta sebagai kendaraan sehari - hari lebih memilih kendaraan umum dibangingkan kendaraan pribadi, dan pada saat biaya ERP menurun responden masih ragu - ragu untuk memilih kendaraan pribadi dan cenderung memilih kendaraan umum.

\section{Analisis Sensitivitas Model Pilihan Taxi Online Terhadap Utilitas ERP dan Taxi Online}

Pada tabel ini dapat dilihat model sensitivitas pilihan Transjakarta terhadap utilitas ERP dan Transjakarta pada Tabel 5 di bawah ini.

Tabel 5 Analisis Sensitivitas ERP dan Transjakarta

\begin{tabular}{|c|c|}
\hline $\begin{array}{c}\text { ERP }-\begin{array}{c}\text { Taxi Online } \\
(\mathrm{Rp})\end{array} \\
\text { Taxi Online }\end{array}$ \\
\hline-15.000 & 3,6728 \\
\hline-20.000 & 3,5358 \\
\hline-25.000 & 3,3988 \\
\hline-30.000 & 3,2618 \\
\hline-35.000 & 3,1248 \\
\hline-40.000 & 2,9878 \\
\hline-45.000 & 2,8508 \\
\hline-50.000 & 2,7138 \\
\hline-55.000 & 2,5768 \\
\hline-60.000 & 2,4398 \\
\hline-65.000 & 2,3028 \\
\hline
\end{tabular}

Dari Tabel 4 dan 5 diatas didapatkan hasil anilisis sensitivitas dengan selisih setiap harga Rp 5.000, pilihan Taxi Online terhadap utilitas ERP dan Taxi Online dapat dilihat bahwa semakin besar biaya ERP responden yang memilih Taxi Online sebagai kendaraan sehari - hari masih ragu - ragu memilih kendaraan pribadi, dan pada saat biaya ERP menurun responden lebih mungkin memilih kendaraan pribadi. Penurunan sensitivitas dapat terlihat pada selisih $35.000-40.000$.

\section{KESIMPULAN}

Berdasarkan hasil penelitian dan pembahasan mengenai sistem Electronic Road Pricing (ERP) dan Kebijakan Parkir terhadap pengendalian kendaraan pribadi di jalan sudirman - Thamrin dapat ditarik kesimpulan :

1. Dari hasil model sensitifitas antara sistem Electronic Road Pricing (ERP) dan Kebijakan Parkir didapatkan grafik analisis sensitifitas yang menunjukan bahwa semakin besar selisih tarif ERP dan Kebijakan Parkir, maka terlihat hasil grafik yang menunjukan responden akan lebih memilih tarif yang lebih murah untuk keperluan tertentu.

2. Dari hasil model sesitifitas ERP dan kebijakan parkir terhadap pendapatan responden didapatkan grafik analisis sensitifitas yang menunjukan bahwa semakin rendah pendapatan maka sensitifitas semakin tinggi. 

Jakarta)

3. Pada hasil perhitungan penggunaan kendaraan pribadi mobil didapatkan hasil bahwa pengguna kendaraan pribadi mobil melihat tarif dan waktu dari kedua sistem tersebut.

4. Perbandingan antara sistem kebijakan parkir terhadap kendaraan umum Transjakarta menunjukan responden masih ragu - ragu untuk menggunakan kendaraan pribadi dan mungkin memilih kendaraan umum untuk transportasi sehari - hari.

5. Perbandingan antara sistem kebijakan parkir terhadap kendaraan umum taxi online menunjukan responden masih ragu - ragu untuk menggunakan kendaraan pribadi dan mungkin memilih kendaraan umum untuk transportasi sehari - hari untuk selisih tarif yang tinggi.

6. Perbandingan antara ERP terhadap kendaraan umum taxi online menunjukan responden lebih melihat tarif ERP untuk menentukan transportasi yang digunakan untuk sehari - hari.

7. Perbandingan antara ERP terhadap kendaraan umum Transjakarta menunjukan responden lebih memilih menggunakan kendaraan umum sebagai kendaraan sehari - hari walaupun tarif ERP menurun.

\section{DAFTAR PUSTAKA}

Abubakar, Iskandar. (2011). Parkir, Pengantar Perencanaan dan Penyelenggaraan Fasilitas Parkir.

Bambang Susantono (Ketua Masyarakat Transportasi Indonesia), Electronic Road Pricing (ERP) Salah Satu Solusi Masalah Kemacetan di Kota Jakarta, Buletin Tata Ruang, September - Oktober 2008

Daniel, J. I., \& Bekka, K. (2000). The environmental impact of highway congestion pricing. Journal of economics.

Jakarta

Dinas perhubungan DKI Jakarta. (2011). Electronic road pricing. Jakarta dinas perhubungan provinsi DKI Jakarta Ekonomi Perkotaan: Electronic Road Pricing (ERP), Minggu, 16 Mei 2010. Jakarta

Indonesia, Undang-Undang No. 29 Tahun 2007 tentang Provinsi DKI Jakarta sebagai Ibukota Negara Republik Indonesia. Dinas Perhubungan DKI Jakarta

Indonesia, Undang-Undang No. 22 Tahun 2009 tentang Lalu Lintas dan Angkutan Jalan. Dinas Perhubungan DKI Jakarta

Indonesia, Undang-Undang No. 28 Tahun 2009 tentang Pajak Daerah dan Retribusi Daerah. Dinas Perhubungan DKI Jakarta

Indonesia, Undang-Undang No. 31 Tahun 2017 tentang Besaran Tarif Layanan Parkir. Dinas Perhubungan DKI Jakarta

Paparan PCI, PCKK, dan Sumitimo Corporation. (2008). "The Study on Jakarta Road Pricing in the Republic of Indonesia." Jakarta 